\title{
Expression, activation, and role of AKT isoforms in the uterus
}

\author{
François Fabi and Eric Asselin \\ Research Group in Molecular Oncology and Endocrinology, Department of Medical Biology, Université du Québec à \\ Trois-Rivières, 3351 Boulevard des Forges, Trois-Rivières, Québec, Canada G9A5H7
}

Correspondence should be addressed to E Asselin; Email: eric.asselin@uqtr.ca

\begin{abstract}
The three isoforms of AKT: AKT1, AKT2, and AKT3, are crucial regulators of both normal and pathological cellular processes. Each of these isoforms exhibits a high level of homology and functional redundancy with each other. However, while being highly similar and structurally homologous, a rising amount of evidence is showing that each isoform possesses specific targets as well as preferential subcellular localization. The role of AKT has been studied extensively in reproductive processes, but isoform-specific roles are yet to be fully understood. This review will focus on the role of AKT in the uterus and its function in processes related to cell death and proliferation such as embryo implantation, decidualization, endometriosis, and endometrial cancer in an isoform-centric manner. In this review, we will cover the activation of AKT in various settings, localization of isoforms in subcellular compartments, and the effect of isoform expression on cellular processes. To fully understand the dynamic molecular processes taking place in the uterus, it is crucial that we better understand the physiological role of AKT isoforms as well as their function in the emergence of diseases.

Reproduction (2014) 148 R85-R95
\end{abstract}

\section{Introduction}

AKT, a serine/threonine kinase, is widely studied in a plethora of biological phenomenon. It has emerged as one of the most critical regulators of cell fate considering its implication in cell cycle control, apoptosis evasion, and metabolic processes, among others. This versatile serine-threonine kinase is central to many human physiological processes; however, because of its fundamental role in many signaling pathways, gain of function of AKT is linked to multiple human diseases. This review focuses on the role of AKT in both normal and pathological processes in the uterus.

The uterus is composed of two major linings; the endometrial and myometrial linings. This review will focus on the former, as it is the compartment that undergoes the most drastic changes throughout the menstrual cycle and pregnancy. The endometrium is further subdivided in two layers: the functional layer and the basal layer. While the basal layer role is to spawn and subsequently support its counterpart, the functional layer is periodically built during every menstrual cycle; this process, the purpose of which is to prepare the endometrium to the possible implantation of a fertilized egg, is influenced by a plethora of factors. The successful implantation of the embryo relies on a highly coordinated interaction between the maternal endometrium and the invading trophoblast. This tightly restricted period of receptivity, which recurs every cycle, is known as the 'window of implantation' and requires a very dynamic regulation of expression of several genes (Kao et al. 2002, Sharma \& Kumar 2012); various mechanisms, which we will explain elaborately further in this review, allow fruitful implantation to take place. The uterus is also involved in many pathological conditions; endometriosis and uterine cancer, the two most prominent of these diseases, will be addressed in this review. Considering the growing body of evidence establishing AKT as a fundamental regulator of many cytokine- and hormonedriven processes, it is natural to study its involvement in the aforementioned processes and mechanisms.

The AKT protein family is constituted by three different isoforms; each of those isoforms is produced by a specific gene. The three distinct isoforms are AKT1/PKB $\alpha$, $\mathrm{AKT} 2 / \mathrm{PKB} \beta$, and $\mathrm{AKT} 3 / \mathrm{PKB} \gamma$; each of those isoforms presents a highly homologous sequence to each other, both functionally and structurally (Fig. 1; Liao \& Hung 2010). The overwhelming body of evidence existing on AKT functions concerns its role in cell survival processes, apoptosis evasion, and cell proliferation (Hennessy et al. 2005, Manning \& Cantley 2007). The cytosolic and inactive form of AKT is recruited to the plasma membrane through phosphorylation of phosphoinositides (Ptdlns) at the 3-position of the inositol ring by phosphoinositide 3-kinase (PI3K), subsequently producing Ptdlns3P/PIP, PtdIns(3,4)P2/PIP 2 , and ultimately PtdIns $(3,4,5) \mathrm{P}_{3} / \mathrm{PIP}_{3}$. 
AKT1

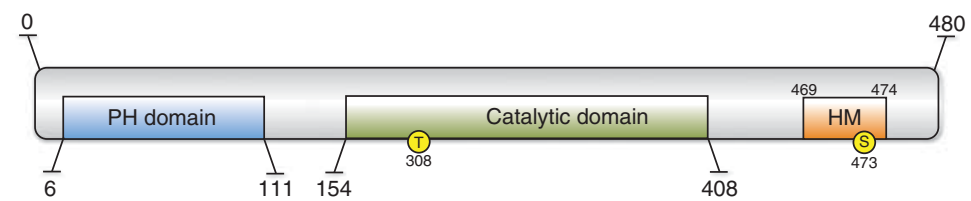

AKT2

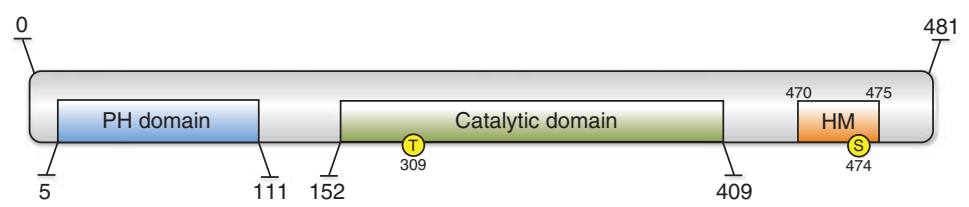

AKT3

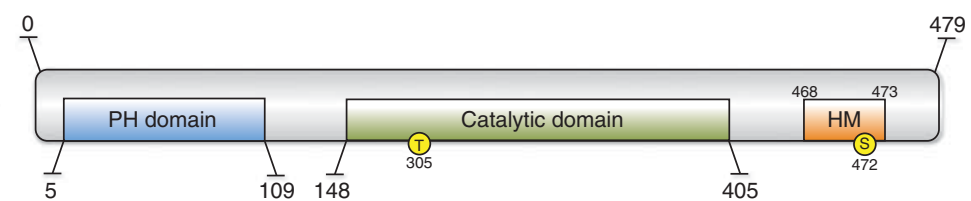

Figure 1 Structure of AKT isoforms: Schematic representation of each AKT isoform with its pleckstrin homology domain (PH domain), its catalytic domain, and its hydrophobic motif. The location of major phosphorylated residues (either $\mathrm{T}$ for threonine or $\mathrm{S}$ for serine) is also shown. Latest (as of May 2014) RefSeq NCBI protein sequence were used (NP_001014431.1, NP_001617.1, and NP_005456.1 respectively).
This phospholipid is anchored in the plasma membrane and will subsequently activate the downstream signaling component by specific binding. Many of those proteins harbor the pleckstrin homology $(\mathrm{PH})$ domain, which recognizes and binds to distinct phosphorylated Ptdlns (Lemmon 2007). The presence of the $\mathrm{PH}$ domain can therefore be considered crucial to both activation and localization of proteins displaying it. AKT is one such protein; its $\mathrm{PH}$ domain binds specifically to $\mathrm{PIP}_{3}$, recruiting and anchoring it to the plasma membrane. It must be noted that some evidences demonstrate that AKT can bind to $\mathrm{PIP}_{3}$ as well as $\mathrm{PIP}_{2}$, as revealed by its crystalline structure as well as in vitro experiments (Franke et al. 1997, Thomas et al. 2002); however, full activation of AKT requires $\mathrm{PIP}_{3}$ (Frech et al. 1997, Denley et al. 2009, Kamimura \& Devreotes 2010). Besides locating it to the plasma membrane, the binding of $\mathrm{PIP}_{3}$ alters the conformation of AKT. This enables its activation by various kinases also present at the membrane by phosphorylation of two crucial residues. The first member of this network is the 3-phosphoinositide-dependent kinase 1 (PDK1), which also displays a PH domain (Mora et al. 2004, Raimondi \& Falasca 2011). PDK1 will activate AKT by phosphorylating its catalytic domain's threonine residue (T308 for AKT1, T309 for AKT2, and T305 for AKT3; Liao \& Hung 2010). On the other hand, the mammalian target of rapamycin complex 2, mTORC2, is the long-sought second major activator of AKT (Sarbassov et al. 2005). It directly phosphorylates the serine residue (S473 for AKT1, S474 for AKT2, and S472 for AKT3). This double phosphorylation fully activates AKT (Yang et al. 2002). One of the most crucial negative regulators of these processes is the lipid protein phosphatase tensin homolog deleted on chromosome 10 (PTEN), which antagonizes AKT activation by catalyzing the dephosphorylation of $\mathrm{PIP}_{3}$, transforming it into $\mathrm{PIP}_{2}$. This reduces AKT localization to the membrane, its conformational changes, and its availability for interaction with its activators (Song et al.
2012). Studies have shown that AKT can be transported to various cellular compartments and organelles. The mechanisms mediating this translocation are still vastly misunderstood. However, the importance of AKT localization in cellular processes, as well as the mechanisms regulating its translocation, is being documented. Recent studies have shown that AKT1 and AKT2 preferentially localized to the cytosol; however, AKT2 was found to colocalize to the mitochondria, suggesting a role in mitochondrial-induced apoptosis as well as metabolism. Finally, AKT3 was found to localize predominantly to the nucleus. These findings emphasize the need to reassess the dogma of plasma membrane activation of AKT (Gonzalez \& McGraw 2009, Santi \& Lee 2010).

Many studies focus on the overall role of AKT, without regards to isoform specificities; indeed, a growing amount of data show that despite the high homology found between isoforms and their resulting functional redundancy, isoforms display specific actions and have distinct roles in both normal and pathological phenomena. To understand these individual roles, many groups have endeavored to generate transgenic mice deficient in each isoforms. Akt1-deficient mice exhibited an increased neonatal mortality as well as a reduced body mass (Chen et al. 2001, Cho et al. 2001a); Akt2-deficient mice developed diabetes-like syndrome, slightly reduced body mass, but no major birth defects (Cho et al. 2001 b, Garofalo et al. 2003); finally, Akt3-deficient mice exhibited reduced brain size due to reduced cell size and number, but did not develop glucose metabolism disorders nor body mass reduction (Easton et al. 2005, Tschopp et al. 2005). Considering the results obtained by these studies, it is evident that AKT isoforms exhibit functional redundancy, as well as non-redundant physiological activities. To further assess these differences, the next natural step was to generate double-knockout animals. Mice with combined deficiencies of both Akt1 and Akt2 displayed majorly impaired skin, bone, and 
muscle development and severely impeded adipogenesis, and died shortly after birth (Peng et al. 2003). Both $A k t 1$ and $A k t 3$ knockout mice died approximately at embryonic day 12 due to defects in growth as well as flawed cardiovascular and nervous system development (Yang et al. 2005). Finally, both Akt2- and Akt3-deficient mice exhibited impaired glucose metabolism, reduced body mass as well as reduced testis and brain weight; despite these defects, however, they were viable and healthy (Dummler et al. 2006). The study also demonstrated that heterozygous mice possessing a single $A k t 1$ at the exclusion of any other isoforms $\left(A k t 1^{+/-}, A k t 2^{-/-}\right.$, and $A k t 3^{-1-}$ ) were viable; this strongly suggests that a single functional allele of $A k t 1$ is sufficient for the mice to develop normally and thrive. Taken together, these findings indicate that each isoform possesses nonoverlapping functions that need to be elucidated to further understand the dynamic and multiple processes in which AKT is involved. This review will focus on the role of AKT isoforms in processes such as implantation, decidualization, endometriosis, and endometrial cancer (EC; Fig. 2).

\section{Implantation}

The implantation process, by which the embryonic trophectoderm invades the maternal uterine luminal epithelium, necessitates a highly coordinated interaction between endometrial cells and trophoblastic cells. This mechanism allows the invading blastocyst to penetrate into the endometrial stroma to eventually come into contact with the maternal blood supply. First, trophoblastic cells of the trophectoderm will be exposed to the maternal endometrium; chemokines and cytokines will enable a molecular dialog between the two structures which will enable the docking and tethering of the embryo to the endometrium, not unlike leukocyte extravasation or metastatic invasion (van den Brule et al. 2005). The trophoblast will then invade the endometrium by penetrating into both the endometrial epithelial cells and its basement membrane; this penetration is enabled by the selective apoptosis of the endometrial epithelial cells (Gu et al. 1994). The invading trophoblast will then come into contact with the endometrial stroma, the uterine blood vessels, and the inner myometrium; the

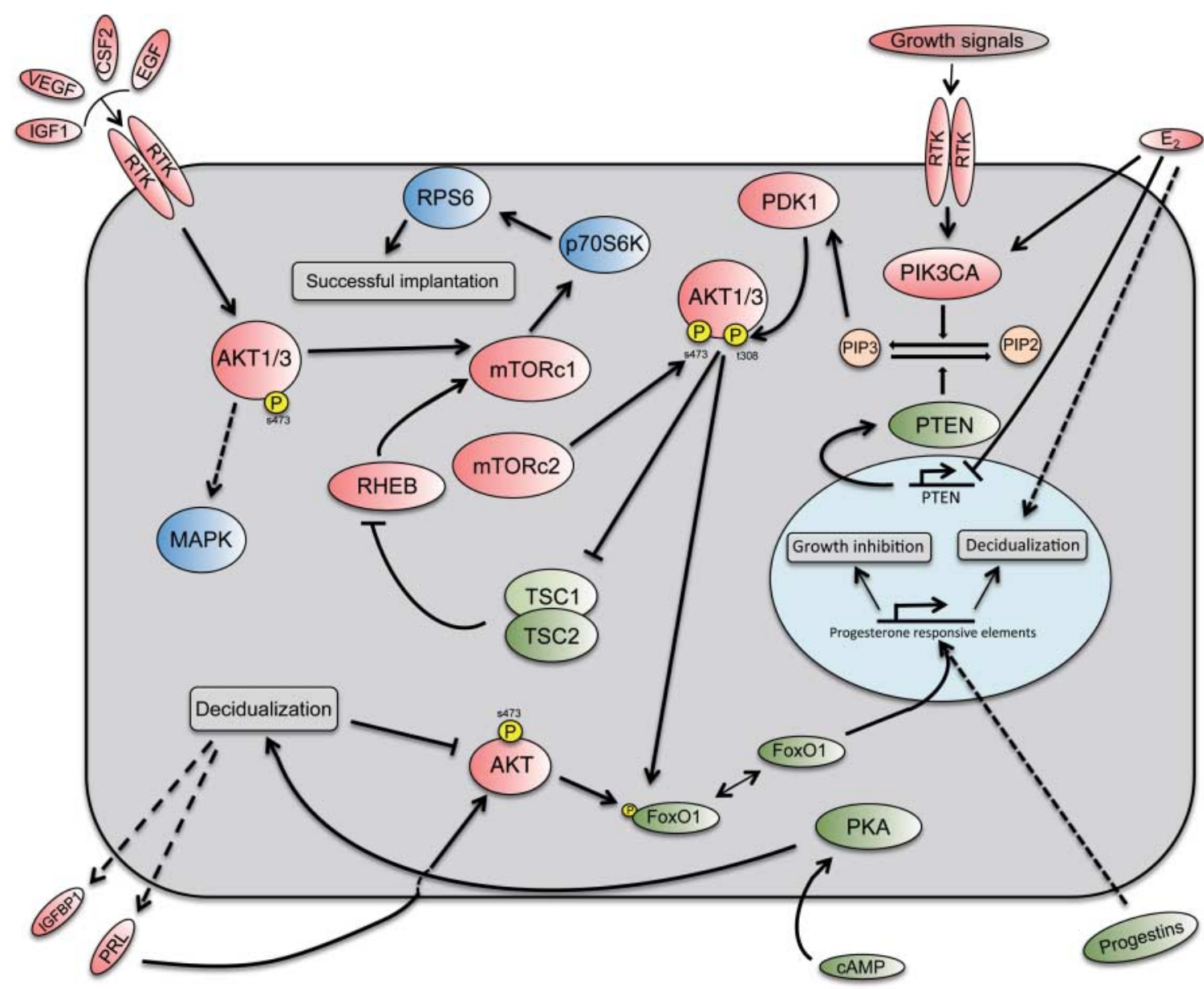

Figure 2 Overview of AKT signaling in the uterus. Schematic representation of crucial regulation elements involving AKT in various physiological and pathological contexts. Green background indicates tumor suppressor proteins, whereas red background denotes potential oncogenes. 
establishment of the placenta and the uteroplacental circulation will conclude this process.

In vitro experiments involving cultured blastocysts from superovulated mice demonstrated that they expressed AKT1 and AKT2 as well as phosphorylated AKT (S473), both majorly at the plasma membrane. The preimplantation embryos also displayed increased phosphorylated AKT (S473) as well as increased glucose uptake in response to insulin, an effect that was mitigated by Wortmannin as well as LY-294002 (both potent PI3K inhibitors) (Riley et al. 2005). This suggests that AKT is necessary for blastocysts' basic glucose metabolism, making it crucial for proper implantation in the maternal endometrium.

In a recent study, the use of cytotrophoblastic SGHPL-5 cells exhibiting features of invasive trophoblast cells that were stably transfected with shRNAmir directed against all three AKT isoforms was discussed. This experiment suggested that AKT1 and AKT3 enable trophoblast migration in response to EGF; however, none of the AKT isoforms seemed to be involved in trophoblast cell proliferation. These effects could be explained by the abrogation of EGF-induced mTORC1 phosphorylation in the absence of both AKT1 and AKT3 (Haslinger et al. 2013). Furthermore, we have shown that each isoform is expressed during both the pregnancy and the pseudopregnancy of the rat. However, we have evidenced that AKT3 was the only phosphorylated isoform at the time of implantation, further strengthening the idea that specific isoforms exert tight control on specific mechanisms (Veillette et al. 2013). However, as stated previously, double knockout mice for $A k t 2$ and $A k t 3$ did not display any birth defect except reduced body mass; the mild phenotype was not influenced by a compensatory expression of AKT1, suggesting that AKT1 and AKT3 possess a similar function in implantation processes (Dummler et al. 2006). This hypothesis is reinforced by the fact that $A k t 1$ - and $A k t 3$-deficient mice were embryonically lethal because of improper placental vasculature, whereas $A k t 1$ and $A k t 2$ double-knockout mice abnormalities were more developmental in nature (Peng et al. 2003, Yang et al. 2005).

Descriptive studies using human placentas have shown that all three AKT isoforms were expressed in first trimester villous and extravillous cytotrophoblasts as well as villous fibroblasts; the syncytium, however, displayed only AKT3 expression. Isoform localization was also variable: AKT1 was detectable primarily not only in the cytoplasm of both villous and extravillous cytotrophoblasts but also in the nuclei, although at a lower level; AKT2 was expressed exclusively in the cytoplasm; AKT3 was most prominent in the nuclei of cells. Experiments using SGHPL-5 cells confirmed these observations (Haslinger et al. 2013). It has also been demonstrated that chorionic gonadotropin, a hormone secreted by the syncytiotrophoblast, promoted trophoblast invasion through AKT-dependent upregulation of
MMP2 as well as increased motility. These effects were not dependent on increased cell proliferation (Prast et al. 2008). Another set of experiments, performed in mice at 5 days of pregnancy, revealed that implantation sites displayed increased PIK3CA, AKT, and RHOA expression, whereas inter-implantation site displayed increased PTEN expression; AKT was most strongly expressed in the stromal cells and luminal epithelium of the implantation site, while phosphorylated AKT (S473) was strongly expressed in stromal cells of the implantation site (Liu et al. 2014). Additionally, the use of contralateral intrauterine injection of LY294002 drastically reduced the number of implanted embryos. These results suggest that the phosphorylation of AKT is important in the process of implantation. Furthermore, these results were not observed when using pseudopregnant mice, allowing us to think that the crosstalk between endometrium and embryo is important in this process. In contrast to these observations, death effector domain-containing protein $(D e d d)^{-/-}$mice implantation sites exhibited decreased AKT protein levels, accompanied by a structural disintegration of the sites and implantation failures; forced expression of AKT1 partially restored polyploidy of the decidual cells, an important marker of successful decidualization, and thus, receptive endometrium (Mori et al. 2011). AKT has also been shown to regulate endometrial cell migration in response to chemoattractants (PDGF-BB, EGF, and FGF2) as well as $17 \beta$-estradiol $\left(E_{2}\right)$, further cementing AKT role in the dynamic process of decidualization (Gentilini et al. 2007). In farm animals, a very recent report has shown that IGF1 provided a crucial stimulatory signal in primary porcine trophectoderm cells (pTr), through the PI3K/Akt pathway. The study evidenced rapid activation of AKT1 upon IGF1 administration, followed by RPS6 activation, a downstream target of mTOR acting as a protein synthesis regulator. The results also suggested that the ERK1/2 MAPK pathway is dependent upon the activation of $\mathrm{PI} 3 \mathrm{~K} / \mathrm{Akt}$ in this context (Jeong et al. 2014a). Another recent report concerning porcine implanting embryos suggested that vascular endothelial growth factor (VEGF; a signal protein capable of stimulating angiogenesis as well as acting as a growth factor), secreted by the receiving endometrium as well as the implanting conceptus, is responsible for the increased migration and proliferation of $\mathrm{pTr}$ cells through the concomitant activation of the PI3K/Akt and MAPK pathways. Again, VEGF induced rapid activation of AKT1 as well as RPS6; this activation was dependent upon PI3K activity as well as mTOR and MAPK activity, as shown by the pharmacological inhibition experiments the authors conducted (Jeong et al. 2014b). Finally, colony-stimulating factor 2 (CSF2), a critical cytokine responsible for proliferation and differentiation of granulocytes and macrophages, is also suggested as an activator of the PI3K/Akt pathway. CSF2 levels were highly enriched during day 10 to day 14 in the pregnant 
porcine endometrium; using pTr cells, CSF2 has also been shown to activate the PI3K/Akt pathway, the MAPK pathway and, ultimately, RPS6 through mTOR activation (Jeong et al. 2014c). All the above-mentioned studies report that ERK1/2 activation was dependent upon AKT1 activation. It should also be noted that, in the porcine context, CSF2 is thought to be secreted in response to conceptus-derived estrogens. Similarly, heightened levels of CSF2 are also found in the bovine uterus during the peri-implantation period through the action of interferon tau (IFNT; Emond et al. 2000, Michael et al. 2006); conversely, the ovine uterus secretes CSF2 during the same period, which in turn enhances IFNT secretion by the trophoblast (Imakawa et al. 1993). These results suggest that regulation of the PI3K/Akt and MAPK pathways by CSF2 could be relevant to other species. Taken together, these results suggest that implantation mechanisms depend on a highly coordinated crosstalk between the PI3K/Akt and MAPK pathways, resulting in the pivotal activation of the mTOR pathway. Both of these networks are thus hypothesized to be crucial in the establishment of reciprocal communication between the implanting embryo and the receiving endometrium.

\section{Decidualization}

During each reproductive cycle, the endometrium undergoes extensive and crucial transformations. The window of receptivity required for implantation to occur is narrow; the endometrium needs to be aptly prepared for implantation through the intricate process of decidualization. Decidualization is initiated through the activation of the cAMP pathway (Gellersen \& Brosens 2003) by the binding of various ligands to a $G$ protein-coupled heteromeric receptor, inducing the production of cAMP in the endometrial stromal cells. Endocrine signaling such as $\mathrm{E}_{2}$ or progesterone are both capable of inducing decidualization by their own. However, the occurrence of decidualization is considerably delayed (Brar et al. 1997, Brosens et al. 1999), when these hormones act without concomitant cAMP signaling; priming by CAMP signaling can thus be considered vital to endometrial cell sensitivity to progesterone.

This process is characterized by extensive differentiation and profound changes in cell function. The most critical change observed in this transformation is the transition of endometrial stromal fibroblasts to secretory, glycogen-filled, epithelial-like cells. This change is accompanied by the secretion of various proteins such as prolactin (PRL) as well as insulin-like growth factorbinding protein 1 (IGFBP1). PRL has been shown to be an inhibitor of apoptosis in various tissues (Al-Sakkaf et al. 2000, Gado et al. 2002, Krishnan et al. 2003) as well as an increasingly relevant tumor biomarker in gynecological cancers (Asai-Sato et al. 2005, Levina et al. 2009). The antiapoptotic effects of PRL on decidual cells also appear to be AKT dependent. The PRL pathway exerts its survival effect through the activation of both MAPK and PI3K (Rao et al. 1995, Yamauchi et al. 1998), and thus, AKT. Additionally, PRL has been shown to induce phosphorylation of Akt (Ser473) as well as its transit from the cytoplasm to the nuclear compartment (Tessier et al. 2001). The role of AKT in decidualization is still vastly unclear and under investigation by various groups. Cultured human endometrial stromal cells undergoing decidualization through estrogen and progesterone supplementation were shown to exhibit a lowered level of phosphorylated AKT (Ser473), indicating that the phosphorylation of AKT might inhibit this process (Yoshino et al. 2003). Interestingly, this inhibition did not appear to be hormone dependent but cAMP dependent. We have also previously shown that both TGF $\beta 2$ and TGF $\beta 3$ could decrease AKT phosphorylation (S473) in rat decidual cells, further involving the decrease in activated AKT with the decidualization process (Caron et al. 2009). Finally, Dedd ${ }^{-/-}$mice were reported to exhibit reduced decidual cell polyploidy probably due to lowered AKT stability; forced expression of AKT1 partially rescued the phenotype (Mori et al. 2011).

It has been demonstrated that the cAMP pathway is necessary in both the initiation and the maintenance of decidualization (Brosens et al. 1999, Tierney et al. 2003), through the activation of various signaling pathways. Insulin, IGF1, and IGF2 have been found to induce the phosphorylation of AKT (S473) in decidualized cells (Capp et al. 2011). On the other hand, decidualization has been linked to the reduced level of phosphorylated AKT and we demonstrated that phosphorylation of all three AKT isoforms is reduced during decidualization (Grenier K and Asselin E, unpublished work; Yoshino et al. 2003); incidentally, both MPA and progestins have been shown to reduce AKT phosphorylation. This reduction has been shown to be responsible for the increased FoxO1 translocation to endometrial stromal cell nuclei. This effect can be explained by the inhibition of AKTdependent phosphorylation of FoxO1 which usually results in its cytoplasmic sequestration (Labied et al. 2006, Zhang et al. 2011). As FoxO1 is of crucial importance in the regulation of progesterone response in endometrial cells (Chen et al. 2011, Kajihara et al. 2013), it is plausible that the modulation of AKT activity is of crucial importance in the establishment of decidualization. AKT is further involved in the decidual cell response to progesterone by stimulating the expression of RRM2, a rate-limiting enzyme in the deoxynucleotide production for DNA synthesis, which could induce the characteristic cell proliferation found during mice decidualization (Lei et al. 2012). However, the specific mechanisms by which each AKT isoform acts in the process of decidualization remain yet to be elucidated.

The dichotomy between CAMP and PRL pathway effects on AKT activity in the decidualization process remains yet to be elucidated; it is possible that an overall reduction of phosphorylated AKT has been observed 
because of its preferential localization to the nucleus at the exclusion of other compartments. In this context, the reduced amount of total AKT would not equate to lowered activity; the concentrated levels of AKT could signal in the nucleus despite cytosolic presence. Furthermore, as the effect of nuclear AKT is vastly unclear, we hypothesize that specific AKT isoforms, displaying distinct cellular sublocalization, possess differential targets and activation pathways.

\section{Endometriosis}

Endometriosis is a very common gynecological disorder, which is estrogen dependent as well as inflammatory in nature, prevalent in $10-15 \%$ of reproductive aged women (Olive \& Pritts 2001). This disease is associated with chronic pelvic pain as well as infertility. The ectopic endometrial implants can be found most commonly on the ovaries, in the Pouch of Douglas, on the uterus, and in the fallopian tubes. The most widely accepted pathogenesis mechanism is a retrograde flow of menses, which would deposit still viable endometrial cells at anomalous locations; this process requires the endometrial cells to attach to the peritoneal mesothelial cells and establish vasculature to permit their proliferation (Sampson 1927, Nunley \& Kitchin 1980, D'Hooghe 1997, Macer \& Taylor 2012, Sundqvist et al. 2012). It is clear, however, that molecular mechanisms are integral in the disease as retrograde menstruation is common (Lucidi et al. 2005).

It has been shown before that the PI3K/Akt signaling pathway is abnormally activated during endometriosis and that this activation was partly responsible for the endometriotic cells' reduced decidual response (Matsuzaki et al. 2005, Cinar et al. 2009); serial analysis of gene expression revealed an increased level of both PI3K and phosphorylated AKT (S473) in endometriotic tissues, probably through the enhanced expression of GAS6, AXL, and ACTN4, responsible for enhanced proliferation and motility (Honda et al. 2008). On the other hand, AKT was not involved in endometriotic cells' expression of EMT markers in response to TNF $\alpha$, a crucial component of inflammation in this disease (Berkkanoglu \& Arici 2003, Grund et al. 2008). Another study highlighted the link between high levels of phosphorylated AKT (S473) an increased Survivin expression, suggesting that Akt permits cell survival and apoptosis avoidance (Zhang et al. 2009). According to its hormone-driven nature, $E_{2}$ was shown to promote endometriotic cell proliferation through the reduced expression of PTEN and the subsequent activation of AKT (Zhang et al. 2010).

Recent studies using high-throughput methods have shown that AKT1 expression was highly elevated in early stages of endometriosis while moderate in later stages of the disease. Higher expression of AKT1 was also linked to dramatically reduced fertility in normal patients. AKT1 was noted to be overwhelmingly located in the cytoplasm of both glandular and stromal cells (Laudanski et al. 2009). Interestingly, studies have linked endometriosis to infertility due to progesterone resistance and failure of endometrial cells to properly decidualize (Bulun et al. 2006). As AKT activation is a hallmark of endometriosis and the inhibition of PI3K and AKT allowed for increased response to MPA and CAMP, it is possible that AKT plays a role in this process; abrogating AKT phosphorylation may reinstate normal localization of FoxO1 and allow for proper decidualization, enhancing fertility of endometriosis stricken women (Engelman 2009, Samartzis et al. 2013).

Increased and decreased expression of phosphorylated AKT (S473) is usually concomitant with similar changes in the activity of mTORc1, leading us to think that one of the primary effect of AKT in endometriosis is the activation of the mTOR pathway (Lucidi et al. 2005, Honda et al. 2008, Zhang et al. 2009). The NFкB pathway also seems to be entwined in the hormonal response as well as survival mechanisms in which AKT is involved (Grund et al. 2008, Zhang et al. 2010, Capp et al. 2011). It seems highly plausible that these proteins are all part of a complexly intertwined signaling network as links have been extensively demonstrated among the mTOR complex, the PTEN/PI3K/Akt axis, and the NFKB signaling pathway.

\section{Cancer}

Multiple malignant tumors can develop in the uterus. However, considering that EC is the most common gynecological malignancy in North America, it will be the focus of this section of the review. Multiple risk factors are linked to the development of this type of tumors, namely obesity, use of tamoxifen adjuvant therapy for the treatment of breast cancer, a family history of polycystic ovarian syndrome, nulliparity, and increased age; $95 \%$ of cases will occur in women aged over 40 years. These risk factors are also distinctly linked to each subtype of EC; this will briefly be discussed further in this section (Arora \& Quinn 2012).

$\mathrm{EC}$ is usually detected at early stages, enabling prompt and effective treatments using a combination of surgery, radiotherapy, and chemotherapy; however, more than $25 \%$ of primary endometrial tumors exhibit metastasis at the moment of detection. This aggressive subtype of tumors presents the most important therapeutic challenge, as they are disseminated and frequently chemoresistant (Muss 1994, Humber et al. 2007). Endometrial carcinomas are generally classified following Bokhman's categorization specifying two major types of endometrial carcinomas, type 1 and type 2 tumors (Bokhman 1983). Type 1 malignancies are generally adenocarcinomas of endometrioid nature and represent the wide majority of endometrial tumors $(\sim 80 \%)$; they usually arise in younger perimenopausal women displaying an atypical hyperplasia, are linked 
to the presence of high levels of estrogens, and do not display highly invasive phenotypes. Type 2 tumors, however, regroup clear cell, squamous, and undifferentiated carcinomas (Ko et al. 2014). These various diseases do not share the risk factors associated with type 1 tumors and present a very bleak prognosis. Finally, while type 2 tumors are often associated with TP53 mutations, type 1 tumors are overwhelmingly associated with PTEN/PI3K pathway mutations (Bansal et al. 2009, Wild et al. 2012). Increased activity of the AKT/PI3K/ mTOR pathway has also been shown to be linked to poor prognosis, regardless of the histological type (Salvesen et al. 2009). Considering its larger incidence and the scope of this review, we will focus thereafter on type $1 \mathrm{EC}$.

Considering the very high proportion of ECs displaying PTEN and PI3K mutations, we are allowed to think that the PI3K/PTEN/Akt axis is of primordial importance in the initiation of the disease (Fig. 3). However, recent data obtained from high-throughput mass spectroscopy and RPPA approaches revealed that $A k t 1$ was mutated in only $1 \%$ of ECs, while no mutation hotspots were detected for both $A k t 2$ and $A k t 3$. This suggests that AKT's effect in EC initiation and progression does not emerge from gain-of-function mutations but rather from the activation of upstream proteins. However, while the great majority of ECs display multiple mutations in the $\mathrm{PI3K} / \mathrm{PTEN} / \mathrm{Akt}$ pathway, mutation in $A k t 1$ has been demonstrated to be sufficient for oncogenic transformation (Shoji et al. 2009).

Progesterone has been long known as a crucial antagonist of EC progression through a variety of mechanisms, notably through cell cycle arrest and apoptosis induction (Yang et al. 2011). However, progestin resistance is a major hurdle in the treatment of EC. The PI3K/Akt pathway has been shown to be activated in progesterone receptor $(P G R)$-deficient cell lines following MPA treatments, an effect that was reversed when reinstating PGR expression. These data suggest that the loss of $P G R$ could potentially induce progesterone-induced apoptosis resistance and instead promote a PGR-independent, Akt-driven survival pathway (Gu et al. 2011). Further data have confirmed

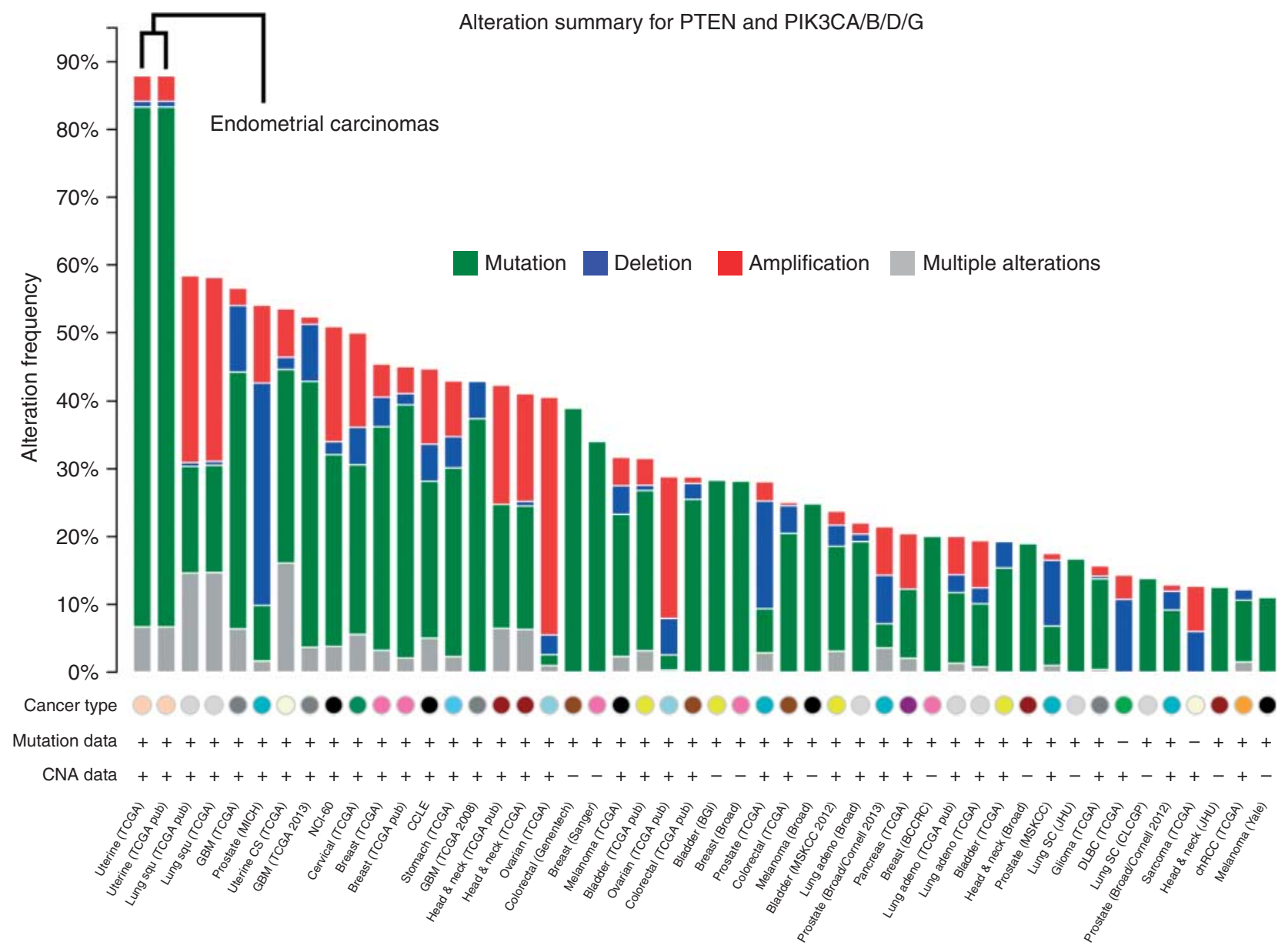

Figure 3 PTEN and PIK3CA/PIK3CB/PIK3CD/PIK3CG are highly mutated in endometrial carcinomas: the histogram shows the frequency of mutations, deletions, amplifications, and multiple alterations in endometrial cancer. An exceedingly high number of tumors display mutations in one of the five genes studied. The histogram was generated using cBioPortal and is produced from 69 distinct studies. 
AKT involvement in this pathway; the use of MK-2206, a novel AKT inhibitor, has been shown to increase progestin response in EC (Pant et al. 2012). On the other hand, estrogen is of prime importance in the development of EC; its unopposed use is a primary risk factor of this disease. Evidences have shown that $E_{2}$ induced the phosphorylation of AKT (S473) through PI3K as well as estrogen receptor alpha (ER $\alpha$; Guo et al. 2006). Furthermore, loss of PTEN has been shown to activate AKT, which in turn is responsible for the phosphorylation of $E R \alpha$ on S167; this phosphorylation subsequently activates it (Vilgelm et al. 2006).

As stated previously, chemoresistance is a major challenge in the treatment of EC. Studies using chemoresistant cell lines and RNAi have been conducted to assess the effect of individual AKT isoforms on drug resistance. Results have shown that while all three isoforms were necessary for optimal cell proliferation, apoptosis evasion, and cell survival, AKT2 was most crucial in chemoresistance (Girouard et al. 2013); this is in accordance with previous studies which suggested that elevated AKT2 activation following cisplatin treatment was responsible for $\mathrm{Bcl} 2$ activation and reduced apoptosis (Rouette et al. 2012). Finally, we have previously shown that AKT regulates PTGS2 expression in $\mathrm{EC}$ through the activation of the NFKB pathway; this, in turn, enables enhanced angiogenesis, tumor invasiveness, and potentially chemoresistance (St-Germain et al. 2004a, b, Chaudhry \& Asselin 2009).

The role of nuclear AKT in cancer has not been extensively investigated as yet. Furthermore, studies showing a link between nuclear accumulation of AKT and cancer progression have been focused on pan-AKT, without regard to isoform specificity (Martelli et al. 2012). Using tissue microarrays, we have recently demonstrated that the nuclei of normal endometrial cell were highly enriched with AKT3, as well as AKT1, albeit at a reduced level; this nuclear enrichment was inverted, with AKT1 being the predominant isoform at the nucleus, upon grade progression of endometrial carcinomas; nuclear localization of AKT was altogether abrogated at a high grade. We could not detect nuclear AKT2 (Fabi $F$ and Asselin E, 2014, results not shown). These results suggest that localization of AKT isoforms may be involved in grade progression of ECs; the nuclear exclusion of AKT3 might lead to dysregulation of normal signaling cascades while the nuclear localization of AKT1 could induce abnormal growth and migratory signals.

\section{Conclusion}

In this review, we have highlighted the major known roles in various reproductive and pathological processes involving AKT isoforms in the uterus. We believe that we have outlined the need for further studies in the expression and activation of AKT isoforms in reproductive process; the interaction between AKT and its partners is still widely unexplored. The role of AKT in the complex network of hormonal signaling is also still unclear. The functional redundancy of AKT isoforms is beginning to emerge, but the distinct targets and partners enabling isoform-specific mechanisms are still unclear. We believe that a deeper understanding of this crucial network could allow for better treatments against infertility, endometriosis, and EC.

\section{Declaration of interest}

The authors declare that there is no conflict of interest that could be perceived as prejudicing the impartiality of the research reported.

\section{Funding}

This work was supported by NSERC.

\section{References}

Al-Sakkaf KA, Mooney LM, Dobson PR \& Brown BL 2000 Possible role for protein kinase $\mathrm{B}$ in the anti-apoptotic effect of prolactin in rat $\mathrm{Nb} 2$ lymphoma cells. Journal of Endocrinology 167 85-92. (doi:10.1677/joe. $0.1670085)$

Arora V \& Quinn MA 2012 Endometrial cancer. Best Practice \& Research. Clinical Obstetrics \& Gynaecology 26 311-324. (doi:10.1016/ j.bpobgyn.2011.12.007)

Asai-Sato M, Nagashima Y, Miyagi E, Sato K, Ohta I, Vonderhaar BK \& Hirahara F 2005 Prolactin inhibits apoptosis of ovarian carcinoma cells induced by serum starvation or cisplatin treatment. International Journal of Cancer 115 539-544. (doi:10.1002/ijc.20810)

Bansal N, Yendluri V \& Wenham RM 2009 The molecular biology of endometrial cancers and the implications for pathogenesis, classification, and targeted therapies. Cancer Control 16 8-13.

Berkkanoglu M \& Arici A 2003 Immunology and endometriosis. American Journal of Reproductive Immunology 50 48-59. (doi:10.1034/j.16000897.2003.00042.x)

Bokhman JV 1983 Two pathogenetic types of endometrial carcinoma. Gynecologic Oncology 15 10-17. (doi:10.1016/0090-8258(83)90111-7)

Brar AK, Frank GR, Kessler CA, Cedars MI \& Handwerger S 1997 Progesterone-dependent decidualization of the human endometrium is mediated by cAMP. Endocrine 6 301-307. (doi:10.1007/BF02820507)

Brosens JJ, Hayashi N \& White JO 1999 Progesterone receptor regulates decidual prolactin expression in differentiating human endometrial stromal cells. Endocrinology 140 4809-4820. (doi:10.1210/endo.140.10.7070)

van den Brule F, Berndt S, Simon N, Coulon C, Le Goarant J, Munaut C, Noel A, Frankenne F \& Foidart JM 2005 Trophoblast invasion and placentation: molecular mechanisms and regulation. Chemical Immunology and Allergy 88 163-180. (doi:10.1159/000087833)

Bulun SE, Cheng YH, Yin P, Imir G, Utsunomiya H, Attar E, Innes J \& Julie Kim J 2006 Progesterone resistance in endometriosis: link to failure to metabolize estradiol. Molecular Cell Endocrinology 248 94-103. (doi:10.1016/j.mce.2005.11.041)

Capp E, Jauckus J, von Eye Corleta H, Toth B, Strowitzki T \& Germeyer A 2011 Does metformin influence the insulin-, IGF I- and IGF II-receptor gene expression and Akt phosphorylation in human decidualized endometrial stromal cells? European Journal of Obstetrics, Gynecology, and Reproductive Biology 158 248-253. (doi:10.1016/j.ejogrb.2011.05.012)

Caron PL, Frechette-Frigon G, Shooner C, Leblanc V \& Asselin E 2009 Transforming growth factor $\beta$ isoforms regulation of Akt activity and XIAP levels in rat endometrium during estrous cycle, in a model of pseudopregnancy and in cultured decidual cells. Reproductive Biology and Endocrinology 7 80. (doi:10.1186/1477-7827-7-80)

Chaudhry P \& Asselin E 2009 Resistance to chemotherapy and hormone therapy in endometrial cancer. Endocrine-Related Cancer 16 363-380. (doi:10.1677/ERC-08-0266) 
Chen WS, Xu PZ, Gottlob K, Chen ML, Sokol K, Shiyanova T, Roninson I, Weng W, Suzuki R, Tobe K et al. 2001 Growth retardation and increased apoptosis in mice with homozygous disruption of the Akt1 gene. Genes Development 15 2203-2208. (doi:10.1101/gad.913901)

Chen S, Gai J, Wang Y \& Li H 2011 FoxO regulates expression of decidual protein induced by progesterone (DEPP) in human endothelial cells. FEBS Letters 585 1796-1800. (doi:10.1016/j.febslet.2011.04.024)

Cho $\mathbf{H}$, Thorvaldsen JL, Chu Q, Feng F \& Birnbaum MJ 2001 a Akt1/PKB $\alpha$ is required for normal growth but dispensable for maintenance of glucose homeostasis in mice. Journal of Biological Chemistry 276 38349-38352. (doi:10.1074/jbc.C100462200)

Cho H, Mu J, Kim JK, Thorvaldsen JL, Chu Q, Crenshaw EB 3rd, Kaestner KH, Bartolomei MS, Shulman GI \& Birnbaum MJ 2001b Insulin resistance and a diabetes mellitus-like syndrome in mice lacking the protein kinase Akt2 (PKB ß). Science 292 1728-1731. (doi:10.1126/ science.292.5522.1728)

Cinar O, Seval Y, Uz YH, Cakmak H, Ulukus M, Kayisli UA \& Arici A 2009 Differential regulation of Akt phosphorylation in endometriosis. Reproductive Biomedicine Online 19 864-871. (doi:10.1016/j.rbmo. 2009.10.001)

Denley A, Gymnopoulos M, Kang S, Mitchell C \& Vogt PK 2009 Requirement of phosphatidylinositol $(3,4,5)$ trisphosphate in phosphatidylinositol 3-kinase-induced oncogenic transformation. Molecular Cancer Research 7 1132-1138. (doi:10.1158/1541-7786.MCR-09-0068)

D'Hooghe TM 1997 Clinical relevance of the baboon as a model for the study of endometriosis. Fertility and Sterility 68 613-625. (doi:10.1016/ S0015-0282(97)00277-X)

Dummler B, Tschopp O, Hynx D, Yang ZZ, Dirnhofer S \& Hemmings BA 2006 Life with a single isoform of Akt: mice lacking Akt2 and Akt3 are viable but display impaired glucose homeostasis and growth deficiencies. Molecular Cell Biology 26 8042-8051. (doi:10.1128/MCB. 00722-06)

Easton RM, Cho H, Roovers K, Shineman DW, Mizrahi M, Forman MS, Lee VM, Szabolcs M, de Jong R, Oltersdorf $\mathbf{T}$ et al. 2005 Role for Akt3/protein kinase $B \gamma$ in attainment of normal brain size. Molecular Cell Biology 25 1869-1878. (doi:10.1128/MCB.25.5.1869-1878.2005)

Emond V, Asselin E, Fortier MA, Murphy BD \& Lambert RD 2000 Interferon-tau stimulates granulocyte-macrophage colony-stimulating factor gene expression in bovine lymphocytes and endometrial stromal cells. Biology of Reproduction 62 1728-1737. (doi:10.1095/ biolreprod62.6.1728)

Engelman JA 2009 Targeting PI3K signalling in cancer: opportunities, challenges and limitations. Nature Reviews Cancer 9 550-562. (doi:10.1038/nrc2664)

Franke TF, Kaplan DR, Cantley LC \& Toker A 1997 Direct regulation of the Akt proto-oncogene product by phosphatidylinositol-3,4-bisphosphate. Science 275 665-668. (doi:10.1126/science.275.5300.665)

Frech M, Andjelkovic M, Ingley E, Reddy KK, Falck JR \& Hemmings BA 1997 High affinity binding of inositol phosphates and phosphoinositides to the pleckstrin homology domain of RAC/protein kinase B and their influence on kinase activity. Journal of Biological Chemistry 272 8474-8481. (doi:10.1074/jbc.272.13.8474)

Gado K, Pallinger E, Kovacs P, Takacs E, Szilvasi I, Toth BE, Nagy G, Domjan G \& Falus A 2002 Prolactin influences proliferation and apoptosis of a human IgE secreting myeloma cell line, U266. Immunology Letters 82 191-196. (doi:10.1016/S0165-2478(02)00008-1)

Garofalo RS, Orena SJ, Rafidi K, Torchia AJ, Stock JL, Hildebrandt AL, Coskran T, Black SC, Brees DJ, Wicks JR et al. 2003 Severe diabetes, age-dependent loss of adipose tissue, and mild growth deficiency in mice lacking Akt2/PKB $\beta$. Journal of Clinical Investigation 112 197-208. (doi:10.1172/JCI16885)

Gellersen B \& Brosens J 2003 Cyclic AMP and progesterone receptor crosstalk in human endometrium: a decidualizing affair. Journal of Endocrinology 178 357-372. (doi:10.1677/joe.0.1780357)

Gentilini D, Busacca M, Di Francesco S, Vignali $M$, Vigano P \& Di Blasio AM 2007 PI3K/Akt and ERK1/2 signalling pathways are involved in endometrial cell migration induced by $17 \beta$-estradiol and growth factors. Molecular Human Reproduction 13 317-322. (doi:10.1093/molehr/gam001)

Girouard J, Lafleur MJ, Parent S, Leblanc V \& Asselin E 2013 Involvement of Akt isoforms in chemoresistance of endometrial carcinoma cells. Gynecologic Oncology 128 335-343. (doi:10.1016/j.ygyno.2012.11.016)
Gonzalez E \& McGraw TE 2009 Insulin-modulated Akt subcellular localization determines Akt isoform-specific signaling. PNAS $\mathbf{1 0 6}$ 7004-7009. (doi:10.1073/pnas.0901933106)

Grund EM, Kagan D, Tran CA, Zeitvogel A, Starzinski-Powitz A, Nataraja S \& Palmer SS 2008 Tumor necrosis factor- $\alpha$ regulates inflammatory and mesenchymal responses via mitogen-activated protein kinase kinase, p38, and nuclear factor $\kappa B$ in human endometriotic epithelial cells. Molecular Pharmacology 73 1394-1404. (doi:10.1124/mol.107.042176)

Gu Y, Jow GM, Moulton BC, Lee C, Sensibar JA, Park-Sarge OK, Chen TJ \& Gibori G 1994 Apoptosis in decidual tissue regression and reorganization. Endocrinology 135 1272-1279. (doi:10.1210/endo.135.3.8070373)

Gu C, Zhang Z, Yu Y, Liu Y, Zhao F, Yin L, Feng Y \& Chen X 2011 Inhibiting the PI3K/Akt pathway reversed progestin resistance in endometrial cancer. Cancer Science 102 557-564. (doi:10.1111/j.1349-7006.2010. 01829.x)

Guo RX, Wei LH, Tu Z, Sun PM, Wang JL, Zhao D, Li XP \& Tang JM 2006 $17 \beta$-Estradiol activates PI3K/Akt signaling pathway by estrogen receptor (ER)-dependent and ER-independent mechanisms in endometrial cancer cells. Journal of Steroid Biochemical Molecular Biology 99 9-18. (doi:10.1016/j.jsbmb.2005.11.013)

Haslinger P, Haider S, Sonderegger S, Otten JV, Pollheimer J, Whitley G \& Knofler M 2013 AKT isoforms 1 and 3 regulate basal and epidermal growth factor-stimulated SGHPL-5 trophoblast cell migration in humans. Biology of Reproduction 88 54. (doi:10.1095/biolreprod.112.104778)

Hennessy BT, Smith DL, Ram PT, Lu Y \& Mills GB 2005 Exploiting the PI3K/AKT pathway for cancer drug discovery. Nature Review Drug Discovery 4 988-1004. (doi:10.1038/nrd1902)

Honda H, Barrueto FF, Gogusev J, Im DD \& Morin PJ 2008 Serial analysis of gene expression reveals differential expression between endometriosis and normal endometrium. Possible roles for AXL and SHC1 in the pathogenesis of endometriosis. Reproductive Biology and Endocrinology 6 59. (doi:10.1186/1477-7827-6-59)

Humber CE, Tierney JF, Symonds RP, Collingwood M, Kirwan J, Williams C \& Green JA 2007 Chemotherapy for advanced, recurrent or metastatic endometrial cancer: a systematic review of Cochrane collaboration. Annals of Oncology 18 409-420. (doi:10.1093/annonc/mdl417)

Imakawa K, Helmer SD, Nephew KP, Meka CS \& Christenson RK 1993 A novel role for GM-CSF: enhancement of pregnancy specific interferon production, ovine trophoblast protein-1. Endocrinology 132 1869-1871. (doi:10.1210/endo.132.4.7681767)

Jeong W, Song G, Bazer FW \& Kim J 2014a Insulin-like growth factor I induces proliferation and migration of porcine trophectoderm cells through multiple cell signaling pathways, including protooncogenic protein kinase 1 and mitogen-activated protein kinase. Molecular Cell Endocrinology 384 175-184. (doi:10.1016/j.mce.2014.01.023)

Jeong W, Kim J, Bazer FW \& Song G 2014b Stimulatory effect of vascular endothelial growth factor on proliferation and migration of porcine trophectoderm cells and their regulation by the phosphatidylinositol-3kinase-AKT and mitogen-activated protein kinase cell signaling pathways. Biology of Reproduction 90 50. (doi:10.1095/biolreprod.113.115873)

Jeong W, Kim J, Bazer FW \& Song G 2014c Proliferation-stimulating effect of colony stimulating factor 2 on porcine trophectoderm cells is mediated by activation of phosphatidylinositol 3-kinase and extracellular signal-regulated kinase $1 / 2$ mitogen-activated protein kinase. PLOS ONE 9 e88731. (doi:10.1371/journal.pone.0088731)

Kajihara T, Brosens JJ \& Ishihara O 2013 The role of FOXO1 in the decidual transformation of the endometrium and early pregnancy. Medical Molecular Morphology 46 61-68. (doi:10.1007/s00795-013-0018-z)

Kamimura Y \& Devreotes PN 2010 Phosphoinositide-dependent protein kinase (PDK) activity regulates phosphatidylinositol 3,4,5-trisphosphatedependent and -independent protein kinase $B$ activation and chemotaxis. Journal of Biological Chemistry 285 7938-7946. (doi:10. 1074/jbc.M109.089235)

Kao LC, Tulac S, Lobo S, Imani B, Yang JP, Germeyer A, Osteen K, Taylor RN, Lessey BA \& Giudice LC 2002 Global gene profiling in human endometrium during the window of implantation. Endocrinology 143 2119-2138. (doi:10.1210/endo.143.6.8885)

Ko EM, Walter P, Clark L, Jackson A, Franasiak J, Bolac C, Havrilesky L, Secord AA, Moore DT, Gehrig PA et al. 2014 The complex triad of obesity, diabetes and race in Type I and II endometrial cancers: prevalence and prognostic significance. Gynecologic Oncology 133 28-32. (doi:10.1016/j.ygyno.2014.01.032) 
Krishnan N, Thellin O, Buckley DJ, Horseman ND \& Buckley AR 2003 Prolactin suppresses glucocorticoid-induced thymocyte apoptosis in vivo. Endocrinology 144 2102-2110. (doi:10.1210/en.2003-0053)

Labied S, Kajihara T, Madureira PA, Fusi L, Jones MC, Higham JM, Varshochi R, Francis JM, Zoumpoulidou G, Essafi A et al. 2006 Progestins regulate the expression and activity of the forkhead transcription factor FOXO1 in differentiating human endometrium. Molecular Endocinology 20 35-44. (doi:10.1210/me.2005-0275)

Laudanski P, Szamatowicz J, Kowalczuk O, Kuzmicki M, Grabowicz M \& Chyczewski L 2009 Expression of selected tumor suppressor and oncogenes in endometrium of women with endometriosis. Human Reproduction 24 1880-1890. (doi:10.1093/humrep/dep175)

Lei W, Feng XH, Deng WB, Ni H, Zhang ZR, Jia B, Yang XL, Wang TS, Liu JL, Su RW et al. 2012 Progesterone and DNA damage encourage uterine cell proliferation and decidualization through up-regulating ribonucleotide reductase 2 expression during early pregnancy in mice. Journal of Biological Chemistry 287 15174-15192. (doi:10.1074/jbc.M111.308023)

Lemmon MA 2007 Pleckstrin homology (PH) domains and phosphoinositides. Biochemical Society Symposium 81-93. (doi:10.1042/BSS0740081)

Levina VV, Nolen B, Su Y, Godwin AK, Fishman D, Liu J, Mor G, Maxwell LG, Herberman RB, Szczepanski MJ et al. 2009 Biological significance of prolactin in gynecologic cancers. Cancer Research 69 5226-5233. (doi:10.1158/0008-5472.CAN-08-4652)

Liao Y \& Hung MC 2010 Physiological regulation of Akt activity and stability. American Journal of Translational Research 2 19-42.

Liu L, Wang Y \& Yu Q 2014 The PI3K/Akt signaling pathway exerts effects on the implantation of mouse embryos by regulating the expression of RhoA. International Journal of Molecular Medicine 33 1089-1096. (doi:10.3892/ijmm.2014.1701)

Lucidi RS, Witz CA, Chrisco M, Binkley PA, Shain SA \& Schenken RS 2005 A novel in vitro model of the early endometriotic lesion demonstrates that attachment of endometrial cells to mesothelial cells is dependent on the source of endometrial cells. Fertility and Sterility 84 16-21. (doi:10.1016/j.fertnstert.2004.10.058)

Macer ML \& Taylor HS 2012 Endometriosis and infertility: a review of the pathogenesis and treatment of endometriosis-associated infertility. Obstetrics and Gynecology Clinics of North America 39 535-549. (doi:10.1016/j.ogc.2012.10.002)

Manning BD \& Cantley LC 2007 AKT/PKB signaling: navigating downstream. Cell 129 1261-1274. (doi:10.1016/j.cell.2007.06.009)

Martelli AM, Tabellini G, Bressanin D, Ognibene A, Goto K, Cocco L \& Evangelisti C 2012 The emerging multiple roles of nuclear Akt. Biochimica Biophysica Acta 1823 2168-2178. (doi:10.1016/j.bbamcr.2012.08.017)

Matsuzaki S, Canis M, Vaurs-Barriere C, Boespflug-Tanguy O, Dastugue B \& Mage G 2005 DNA microarray analysis of gene expression in eutopic endometrium from patients with deep endometriosis using laser capture microdissection. Fertility and Sterility 84 (Suppl 2) 1180-1190. (doi:10.1016/j.fertnstert.2005.04.041)

Michael DD, Wagner SK, Ocon OM, Talbot NC, Rooke JA \& Ealy AD 2006 Granulocyte-macrophage colony-stimulating-factor increases interferon- $\tau$ protein secretion in bovine trophectoderm cells. American Journal of Reproductive Immunology 56 63-67. (doi:10.1111/j.16000897.2006.00390.x)

Mora A, Komander D, van Aalten DM \& Alessi DR 2004 PDK1, the master regulator of AGC kinase signal transduction. Seminar in Cellular, Molecular and Developmental Biology 15 161-170. (doi:10.1016/ j.semcdb.2003.12.022)

Mori M, Kitazume M, Ose R, Kurokawa J, Koga K, Osuga Y, Arai S \& Miyazaki T 2011 Death effector domain-containing protein (DEDD) is required for uterine decidualization during early pregnancy in mice. Journal of Clinical Investigation 121 318-327. (doi:10.1172/JCI44723)

Muss HB 1994 Chemotherapy of metastatic endometrial cancer. Seminars in Oncology 21 107-113.

Nunley WC Jr \& Kitchin JD 3rd 1980 Congenital atresia of the uterine cervix with pelvic endometriosis. Archives of Surgery 115 757-758. (doi:10.1001/archsurg.1980.01380060055015)

Olive DL \& Pritts EA 2001 Treatment of endometriosis. New England Journal of Medicine 345 266-275. (doi:10.1056/NEJM200107263450407)

Pant A, Lee II, Lu Z, Rueda BR, Schink J \& Kim JJ 2012 Inhibition of AKT with the orally active allosteric AKT inhibitor, MK-2206, sensitizes endometrial cancer cells to progestin. PLOS ONE 7 e41593. (doi:10. 1371/journal.pone.0041593)
Peng XD, Xu PZ, Chen ML, Hahn-Windgassen A, Skeen J, Jacobs J, Sundararajan D, Chen WS, Crawford SE, Coleman KG et al. 2003 Dwarfism, impaired skin development, skeletal muscle atrophy, delayed bone development, and impeded adipogenesis in mice lacking Akt1 and Akt2. Genes Development 17 1352-1365. (doi:10.1101/gad. 1089403)

Prast J, Saleh L, Husslein H, Sonderegger S, Helmer H \& Knofler M 2008 Human chorionic gonadotropin stimulates trophoblast invasion through extracellularly regulated kinase and AKT signaling. Endocrinology 149 979-987. (doi:10.1210/en.2007-1282)

Raimondi C \& Falasca M 2011 Targeting PDK1 in cancer. Current Medicinal Chemistry 18 2763-2769. (doi:10.2174/092986711796011238)

Rao YP, Buckley DJ \& Buckley AR 1995 Rapid activation of mitogenactivated protein kinase and p21ras by prolactin and interleukin 2 in rat Nb2 node lymphoma cells. Cell Growth \& Differentiation 6 $1235-1244$.

Riley JK, Carayannopoulos MO, Wyman AH, Chi M, Ratajczak CK \& Moley KH 2005 The PI3K/Akt pathway is present and functional in the preimplantation mouse embryo. Developmental Biology 284 377-386. (doi:10.1016/j.ydbio.2005.05.033)

Rouette A, Parent S, Girouard J, Leblanc V \& Asselin E 2012 Cisplatin increases B-cell-lymphoma-2 expression via activation of protein kinase $\mathrm{C}$ and Akt2 in endometrial cancer cells. International Journal of Cancer 130 1755-1767. (doi:10.1002/ijc.26183)

Salvesen HB, Carter SL, Mannelqvist M, Dutt A, Getz G, Stefansson IM, Raeder MB, Sos ML, Engelsen IB, Trovik J et al. 2009 Integrated genomic profiling of endometrial carcinoma associates aggressive tumors with indicators of PI3 kinase activation. PNAS 106 4834-4839. (doi:10.1073/ pnas.0806514106)

Samartzis EP, Noske A, Dedes KJ, Fink D \& Imesch P 2013 ARID1A mutations and PI3K/AKT pathway alterations in endometriosis and endometriosis-associated ovarian carcinomas. International Journal of Molecular Sciences 14 18824-18849. (doi:10.3390/ ijms140918824)

Sampson JA 1927 Metastatic or embolic endometriosis, due to the menstrual dissemination of endometrial tissue into the venous circulation. American Journal of Pathology 3 93-110.43.

Santi SA \& Lee H 2010 The Akt isoforms are present at distinct subcellular locations. American Journal of Physiology. Cell Physiology 298 C580-C591. (doi:10.1152/ajpcell.00375.2009)

Sarbassov DD, Guertin DA, Ali SM \& Sabatini DM 2005 Phosphorylation and regulation of $\mathrm{Akt} / \mathrm{PKB}$ by the rictor-mTOR complex. Science $\mathbf{3 0 7}$ 1098-1101. (doi:10.1126/science.1106148)

Sharma A \& Kumar P 2012 Understanding implantation window, a crucial phenomenon. Journal of Human Reproductive Sciences 5 2-6. (doi:10.4103/0974-1208.97777)

Shoji K, Oda K, Nakagawa S, Hosokawa S, Nagae G, Uehara Y, Sone K, Miyamoto $\mathrm{Y}$, Hiraike $\mathrm{H}$, Hiraike-Wada $\mathbf{O}$ et al. 2009 The oncogenic mutation in the pleckstrin homology domain of AKT1 in endometrial carcinomas. British Journal of Cancer 101 145-148. (doi:10.1038/sj.bjc. 6605109)

Song MS, Salmena L \& Pandolfi PP 2012 The functions and regulation of the PTEN tumour suppressor. Nature Review. Molecular and Cellular Biology 13 283-296. (doi:10.1038/nrm3330)

St-Germain ME, Gagnon V, Mathieu I, Parent S \& Asselin E 2004a Akt regulates COX-2 mRNA and protein expression in mutated-PTEN human endometrial cancer cells. International Journal of Oncology 24 1311-1324. (doi:10.3892/ijo.24.5.1311)

St-Germain ME, Gagnon V, Parent S \& Asselin E 2004b Regulation of COX-2 protein expression by Akt in endometrial cancer cells is mediated

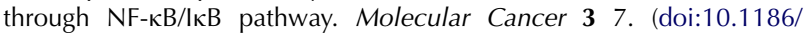
1476-4598-3-7)

Sundqvist J, Andersson KL, Scarselli G, Gemzell-Danielsson K \& Lalitkumar PG 2012 Expression of adhesion, attachment and invasion markers in eutopic and ectopic endometrium: a link to the aetiology of endometriosis. Human Reproduction 27 2737-2746. (doi:10.1093/ humrep/des220)

Tessier C, Prigent-Tessier A, Ferguson-Gottschall S, Gu Y \& Gibori G 2001 $\mathrm{PRL}$ antiapoptotic effect in the rat decidua involves the PI3K/protein kinase B-mediated inhibition of caspase-3 activity. Endocrinology 142 4086-4094. (doi:10.1210/endo.142.9.8381) 
Thomas CC, Deak M, Alessi DR \& van Aalten DM 2002 High-resolution structure of the pleckstrin homology domain of protein kinase b/akt bound to phosphatidylinositol (3,4,5)-trisphosphate. Current Biology 12 1256-1262. (doi:10.1016/S0960-9822(02)00972-7)

Tierney EP, Tulac S, Huang ST \& Giudice LC 2003 Activation of the protein kinase A pathway in human endometrial stromal cells reveals sequential categorical gene regulation. Physiological Genomics 16 47-66. (doi:10.1152/physiolgenomics.00066.2003)

Tschopp O, Yang ZZ, Brodbeck D, Dummler BA, Hemmings-Mieszczak M, Watanabe T, Michaelis T, Frahm J \& Hemmings BA 2005 Essential role of protein kinase B $\gamma$ (PKB $\gamma / A k t 3)$ in postnatal brain development but not in glucose homeostasis. Development 132 2943-2954. (doi:10.1242/ dev.01864)

Veillette A, Grenier K, Brasseur K, Frechette-Frigon G, Leblanc V, Parent S \& Asselin E 2013 Regulation of the PI3-K/Akt survival pathway in the rat endometrium. Biology of Reproduction 88 79. (doi:10.1095/biolreprod. 112.107136)

Vilgelm A, Lian Z, Wang H, Beauparlant SL, Klein-Szanto A, Ellenson LH \& Di Cristofano A 2006 Akt-mediated phosphorylation and activation of estrogen receptor $\alpha$ is required for endometrial neoplastic transformation in Pten+/- mice. Cancer Research 66 3375-3380. (doi:10.1158/ 0008-5472.CAN-05-4019)

Wild PJ, Ikenberg K, Fuchs TJ, Rechsteiner M, Georgiev S, Fankhauser N, Noske A, Roessle M, Caduff R, Dellas A et al. 2012 p53 suppresses type II endometrial carcinomas in mice and governs endometrial tumour aggressiveness in humans. EMBO Molecular Medicine 4 808-824. (doi:10.1002/emmm.201101063)

Yamauchi T, Kaburagi Y, Ueki K, Tsuji Y, Stark GR, Kerr IM, Tsushima T, Akanuma Y, Komuro I, Tobe K et al. 1998 Growth hormone and prolactin stimulate tyrosine phosphorylation of insulin receptor substrate$1,-2$, and -3 , their association with p85 phosphatidylinositol 3-kinase (PI3-kinase), and concomitantly PI3-kinase activation via JAK2 kinase. Journal of Biological Chemistry 273 15719-15726. (doi:10.1074/jbc.273. 25.15719)
Yang J, Cron P, Good VM, Thompson V, Hemmings BA \& Barford D 2002 Crystal structure of an activated Akt/protein kinase B ternary complex with GSK3-peptide and AMP-PNP. Nature Structural Biology 9 940-944. (doi:10.1038/nsb870)

Yang ZZ, Tschopp O, Di-Poi N, Bruder E, Baudry A, Dummler B, Wahli W \& Hemmings BA 2005 Dosage-dependent effects of Akt1/protein kinase $\mathrm{B} \alpha(\mathrm{PKB} \alpha)$ and $\mathrm{Akt} 3 / \mathrm{PKB} \gamma$ on thymus, skin, and cardiovascular and nervous system development in mice. Molecular Cell Biology 25 10407-10418. (doi:10.1128/MCB.25.23.10407-10418.2005)

Yang S, Thiel KW \& Leslie KK 2011 Progesterone: the ultimate endometrial tumor suppressor. Trends in Endocrinology and Metabolism 22 145-152. (doi:10.1016/j.tem.2011.01.005)

Yoshino O, Osuga Y, Hirota Y, Koga K, Yano T, Tsutsumi O \& Taketani Y 2003 Akt as a possible intracellular mediator for decidualization in human endometrial stromal cells. Molecular Human Reproduction 9 265-269. (doi:10.1093/molehr/gag035)

Zhang H, Li M, Zheng X, Sun Y, Wen Z \& Zhao X 2009 Endometriotic stromal cells lose the ability to regulate cell-survival signaling in endometrial epithelial cells in vitro. Molecular Human Reproduction 15 653-663. (doi:10.1093/molehr/gap069)

Zhang H, Zhao X, Liu S, Li J, Wen Z \& Li M $201017 \beta E 2$ promotes cell proliferation in endometriosis by decreasing PTEN via NFKB-dependent pathway. Molecular Cell Endocrinology 317 31-43. (doi:10.1016/j.mce. 2009.11.009)

Zhang X, Tang N, Hadden TJ \& Rishi AK 2011 Akt, FoxO and regulation of apoptosis. Biochimica Biophysica Acta 1813 1978-1986. (doi:10.1016/ j.bbamcr.2011.03.010)

Received 27 May 2014

First decision 2 July 2014

Accepted 7 August 2014 